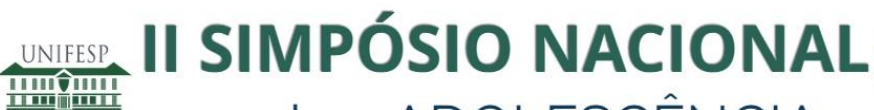 sobre ADOLESCÊNCIA: Vulnerabilidades, Protagonismos e Desafios
}

\section{Mídia e adolescência: um caminho que se cruza e se afasta}

\author{
Ana Laura Schliemann \\ Pontifícia Universidade Católica de São Paulo \\ Carolina Tomishige Alves Lima \\ Pontifícia Universidade Católica de São Paulo \\ E-mail: carolinatlima@gmail.com \\ Pontifícia Universidade Católica de São Paulo \\ Juliana Guimarães Ferreira \\ Pontifícia Universidade Católica de São Paulo \\ E-mail: juhguif@gmail.com
}

\section{Como citar:}

SCHLIEMANN, Ana Laura; LIMA, Carolina Tomishige Alves; FERREIRA, Juliana Guimarães. Mídia e adolescência: um caminho que se cruza e se afasta. In: SIMPÓSIO NACIONAL SOBRE ADOLESCÊNCIA: VULNERABILIDADE, PROTAGONISMOS E DESAFIOS, 2, 2016, São Paulo. Anais...[S. I.]: 2016. p. 33 - 34. DOI: http://dx.doi.org/10.22388/2525-5894.2016.011

Esse trabalho é fruto da disciplina de Psicologia do Desenvolvimento III e discute a influência midiática em adolescentes do sexo feminino. A TV é um item de essencial importância na casa da maioria das famílias. Crianças, adolescentes e adultos passam cada vez mais tempo diante do aparelho assistindo aos mais diversos programas, e com o surgimento da Netflix esse tempo aumentou exponencialmente. Dados da Pesquisa Brasileira de Mídia de 2015 revelam que os brasileiros costumam passar em média 3 horas e meia por dia assistindo TV. Com tanto tempo de exposição, é de extrema importância que se investigue qual seria o impacto que isso poderia causar para o telespectador. Um dos gêneros de programas mais assistidos e fidelizados pelo público são os seriados para o público adolescente, tais como Teen Wolf, Vampire Diaries, Glee e Pretty Little Liars. Trazendo uma proposta de série "de adolescentes para adolescentes", esses programas costumam apresentar como personagens principais heróis e heroínas que ainda estão no Ensino Médio. Ao invés de escalarem um elenco com as respectivas idades dos personagens, as emissoras acabam por escolher atrizes e atores com idade que pode variar de 5 até 10 anos dos personagens originais. Quem sofre mais com isso é o público alvo, particularmente adolescentes do sexo feminino. Utilizando-se de padrões irreais de beleza, associados a um elenco excessivamente estereotipado, os seriados criam as adolescentes "ideais": perfeitas, maravilhosas, impecáveis, produzindo, para os telespectadores, figuras inatingíveis, tanto em fatores estéticos, quanto comportamentais. 0 trabalho teve como objetivo abordar a temática da influência midiática em adolescentes do sexo feminino. Como método foi desenvolvido um vídeo confeccionado após uma revisão de literatura, utilizando a teoria de Erik Erikson. Foi observada uma grande escassez de materiais específicos a respeito do tema escolhido, 
tendo que se recorrer a textos de blogs ou fazer analogias com pesquisas de outros temas para poder criar uma base teórica para o trabalho. Constatou-se que é no período da adolescência que ocorre a formação da identidade, não só através da experimentação de papéis, mas também pela reflexão e observação do seu meio. Conforme Erickson, a possibilidade do jovem alcançar um senso de identidade de ego significativo dependerá do senso de confiança, autonomia, iniciativa e produtividade com que ele atingir a adolescência, que seria diretamente influenciada pelos pais desde a infância. Caso contrário, o jovem poderá apresentar confusão de papéis, isto é, não saber de si ou com o que se identifica. Pode ocorrer ainda a busca uma identidade oposta ao seu círculo social, que foi chamado por Erikson de "identidade negativa". É nesse sentido que a mídia causa um impacto que pode ser desmedido e perigoso. Adolescentes, cada vez mais conectados a diferentes tipos de tecnologia, são verdadeiramente bombardeados com imagens que vendem ideais estéticos e comportamentais completamente inatingíveis. Inúmeros filmes e séries utilizam atores muito mais velhos para representar personagens de 15 ou 16 anos, como é o caso das séries One Tree Hill e Gossip Girl. A partir da revisão da literatura e de blogs foi confeccionado um vídeo utilizando a versão gratuita do software PowToon. No trabalho em vídeo tentou-se utilizar de uma linguagem mais acessível fazendo uso de animação com apenas uma trilha sonora instrumental. Já em seus primeiros momentos é apresentado a personagem principal: uma adolescente do sexo feminino. A partir daí evidenciam-se seus pontos de interesse, como séries de televisão (Pretty Little Liars, Gossip Girl e Glee) e redes sociais como o Instagram. Discutiu-se então como a garota teria um sentimento de starstruck, fazendo das mais diversas personagens de séries e grandes figuras das redes sociais seus "role models" na esperança de um dia poder tornar-se como elas. Acompanha-se as tentativas feitas pela protagonista para chegar a esse objetivo - todas em vão. Depois de diversas tentativas fracassadas ela então percebe que não poderia se tornar a figura idealizada que tanto sonhava ser, pois na verdade essa figura é irreal. A chegada a essa conclusão traz, evidentemente, uma grande tristeza à essa protagonista. O vídeo termina mostrando o quanto a busca por esse ideal irreal, inatingível pode causar sofrimento para as jovens adolescentes.

Palavras-chave: Autoimagem. Mídia. Seriados. Adolescência. Psicologia. 